\title{
Reducing the length of stay in hospital
}

\author{
MICHAEL RYAN
}

Unlike their British counterparts, Soviet health care planners have long adhered to a strategy of adding to the number of hospital beds each year. Consequently, the proportion of the population admitted to hospital has grown steadily; by 1983 this had reached the historically high level of $24 \cdot 7 \%$. Although the extra capacity has been advantageous in several respects, it can scarcely have encouraged rigorous assessment of traditional practices that entail the use of expensive inpatient facilities.

Two key series of official statistics for 1974-81 support this contention. The first records that the average duration of stay during this period lengthened from $17 \cdot 4$ to $17 \cdot 6$ days in urban units and from 13.4 to 14.6 days in rural hospitals. The second series shows that only a marginal improvement occurred in the average number of days in a year on which a hospital bed was being used rather than lying empty: the figure rose slightly from 326 to 328 in urban areas and from 311 to 312 in the countryside. These data relate to all the units for which the Union Health Ministry is responsible, and hence to most Soviet hospitals.

\section{In the Ukraine}

Recently, however, the health service has not been exempt from the Party's general drive for economy in the use of resources and improvement in the quality of work performed. Another, obviously related, demand is for more effective management throughout the Soviet economy. These "orders of the day" can be regarded as the broad political backdrop against which the First Deputy Health Minister of the Ukraine presented an account of shortcomings and the steps taken to remedy them in the hospitals and policlinics of that republic.

At the start of his article Dr Zelinski acknowledges the value of the many additional beds brought into commission during the previous four years of the then current five year plan. ${ }^{1}$ These had facilitated consolidation and expansion of the major types of unit providing inpatient treatment-namely, the regional, town, and (in rural areas) district centre hospitals. The republic's rate of admissions was 260 per 1000 population, with virtual equality between urban and rural areas. By equalising access to hospital, the Ukrainian Health Ministry was putting into practice the state's policy of raising living conditions in the countryside to a level similar to that in the towns.

Nevertheless, the deputy minister makes clear that improvements in the crude quantitative indicators of bed numbers and equipment in hospitals are insufficient proof of the successful administration of the health service. Another important objective is the more economical use of beds, as measured by a reduction in the average duration of stay. For this to be achieved, Dr Zelinski implies, care in hospital must not be seen as an isolated event but as

Centre of Russian and East European Studies, University College of Swansea, Swansea SA2 8PP

MICHAEL RYAN, MA, PHD, lecturer in politics and Russian studies one part of a process in which continuity and coordination of activity are essential for efficient management of patients.

A programme of care for patients who have suffered myocardial infarction is an example of the practical application of such a system in the Ukraine. Overriding the administrative boundaries of different types of unit, it links the work of specialised "brigades" of the emergency aid service, cardiological and rehabilitation departments in hospitals, sanatoria, and specialist rooms in policlinics. As proof of its success, Dr Zelinski reports that "up to 90\%" of patients who had suffered infarction are now returning to work. Fifteen years ago, by contrast, the proportion was only $50 \%$.

\section{Making the diagnosis}

Turning to the debit side of the account, he then acknowledges that "Many hospitals are being utilised irrationally and the demand for hospitalisation is not being fully satisfied." This criticism does not reflect the view of the Health Ministry alone, having been established by investigations in a number of regions by the appropriate committees of the powerful people's control committees of the Union and the republic. Their conclusions and analysis of data relating to the activity of health care units enabled the ministry to identify two broad groups of negative features that called for remedy.

The first lies outside the control of hospital staff as it consists of inadequacies of organisation, diagnosis, and treatment at the policlinic stage. As had been discovered in the Zakarpatsk and Khmelnitski regions, these shortcomings have immediate consequences for the workloads of the hospitals. Assessment by experts showed that "up to $20 \%$ " of inpatients should not have been admitted in the first place. Most of the unnecessary admissions were to neurology, general medicine, and urology departments, many of them requiring only radiography, endoscopy, histology, and other investigations. Others needed minor operations, which, the article states, could have been performed in policlinics.

Here it should be emphasised that this is by no means the only Soviet investigation to produce such results. Some years ago it was found that $14 \%$ of inpatients suffering from "pathology of the nervous system and endocrinological diseases" could have been treated on an ambulatory basis. This also applied to $12 \%$ of those with diseases of the circulatory system and $8 \%$ of inpatients in ear, nose, and throat departments. ${ }^{2}$

The second set of factors causing inefficient use of hospital beds arises from the "low level" of managerial competence in the units themselves and in the various supervisory agencies. The deputy minister specifically blames the regional health departments, the chief specialists (in clinical divisions such as general medicine) and the organisation and management departments of regional hospitals. One example of "inadequate control" is the variation among regions in the duration of stay for the same condition. Thus for hypertension the average duration in the Kherson region is 13.6 days, but in Kiev it is $19 \cdot 6$ days. For severe myocardial infarction the figures range from 26.3 in the Crimea and 26.8 in the Zaporozhsk region to $39 \cdot 8$ and $41 \cdot 1$ in the Vinnitsa and Volina 
regions, respectively. Differences in the qualifications of staff are excluded as an explanatory factor.

In an attempt to discover the reasons for such variations, officials made on the spot inquiries, which generated evidence of "a basic lack of concern regarding the use of the bed complement" on the part of hospital directors, all of whom are doctors. Once this conclusion had been drawn the Ukrainian Health Ministry introduced a set of emergency measures, apparently from 1983 onwards.

\section{The ministry's prescription}

Importantly, the first move aimed at raising the range and quality of investigations carried out at the prehospital stage. This entailed improvement of the equipment in existing policlinics and the commissioning, under the five year plan, of new policlinics with a combined capacity of almost 100000 visits per shift.

Nevertheless, however well equipped those ambulatory units might be, Dr Zelinski declared, it is the calibre of their staff that determines success. At this point he virtually admits that the "uchastok" (sector) doctors represent the weak link in the chain, by stating that half of them "do not yet have adequate experience and length of service." He goes on to note that many of them are following various postgraduate courses, which suggests that the ministry regards more or better training as the only practical measure to adopt in this case.

Although it would not be within the ministry's jurisdiction to alter the status of first line doctors fundamentally, it certainly has the power to specify procedures that these and other doctors must follow in their clinical practice. In what seems a fairly thoroughgoing exercise the ministry compiled and issued documents listing obligatory investigations and regimens of treatment for over 300 of the more common diseases. Medical indications for admission to hospital have also been codified.

The article also makes clear that the ministry sought to make universal good practices that had been initiated at local level by "leading collectives." For example, Hospital No 11 in Krivoi Rog was the venue for a seminar at which deputy chief doctors studied organisational principles and practices intended to reduce the duration of a patient's stay in hospital. One of these was "the intensification of the diagnostic and curative process."

\section{Improvements achieved}

That there is substantial scope for such savings is made clear by the article's reference to the experience of the Ivana Franko regional hospital. Formerly, the time taken for histological investigations varied from seven to 14 days; after new equipment and methods of work had been introduced the results became available within a day or so.

The article also refers to organisational innovations intended to facilitate the flow of information between different health care units. This had been recognised as a problem area by the ministry's experts; their on the spot inquiries showed that unjustifiable duplication of laboratory and instrumental investigations took place and that $5-12 \%$ of patients had been admitted to a ward of the wrong specialty.

Given the general tenor of Dr Zelinski's account, it should come as no surprise that he concluded by claiming an initial degree of $\tilde{\sigma}$ success for the initiatives taken by his ministry. He pointed to an $\frac{5}{3}$ improvement already achieved in the average number of days on which a hospital bed is in use; this figure rose from 339 in 1983 to 340 in 1984 . Over the same period the average duration of stay had ? also moved in the right direction, declining by 0.2 of a day to stand at $16 \cdot 4$ days. Consequently, several thousand more patients could be admitted to hospitals in the Ukraine.

The author thanks the Nuffield Foundation for the award of a Nuffield Social Science Research Fellowship.

\section{References}

1 Zelinski A. Bolnichnava koika: kak yeyo luchshe ispolzovat? Meditsinskaya Gazeta 1985 April 10:2 Malov NI. Churakov VI. Sovremennie osnovi i metodi planirovaniva razzitiva zdravookhranenty. Moscow: Ekonomika, 1981:112-3.

Accepled 2.3 fanuan 1986
In the "British National Formulary" it states that measles vaccine should be given with a specially diluted immunoglobulin for individuals who have had non-febrile convulsions. In the recommendations from the DHSS circulated in 1984 there is no mention for the need for special precautions to be taken with children who have had previous convulsions. What advice should doctors take?

If the "recommendations from the DHSS circulated in 1984" refers to the booklet "Immunisation against infectious disease" prepared by the Joint Committee on Vaccination and Immunisation then paragraphs 7.3.6 and 7.3.7 on page 33 do refer to this problem and agree with the information in the British National Formulary. This advice should be followed-namely, that children with a personal history of convulsions (not just non-febrile ones) or whose parents or siblings have a history of idiopathic epilepsy should receive a low dose of measles immunoglobulin at the same time as measles vaccine. The principle behind this is to allow replication of measles vaccine virus but further reduce the incidence of adverse reactions, particularly febrile ones. The immunoglobulin, at a dose of $0.4-0.8 \mathrm{IU} / \mathrm{kg}$ body weight, should be given intramuscularly at a different site, and is most conveniently dispensed in a dilute preparation $(12 \mathrm{IU} / \mathrm{ml}$ in Scotland, 10.6 $\mathrm{IU} / \mathrm{ml}$ in England and Wales). This use of immunoglobulin should not be confused with the use of it in higher doses to prevent spread of wild measles virus to infants or the immunosuppressed. Higher doses are more conveniently given in lower volumes from stronger preparations such as a normal immunoglobulin and human measles immunoglobulin (used instead of normal immunoglobulin in Scotland), which may be expected to contain $50 \mathrm{IU} / \mathrm{ml}$ and $250 \mathrm{IU} / \mathrm{ml}$ of measles antibody respectively. A high dose of immunoglobulin given inadvertently at the time of measles immunisation is likely to prevent vaccine virus replication and the subsequent development of immunity as a recent case showed. -GLYN R wILLIAMs, lecturer in infectious diseases, Glasgow.

1 Anonymous. Measles vaccine and immunoglobulin. Communicable Diseases Scotland Weekly Report 1985;85/38:12.
A patient has had a transurethral prostatectomy for a benign enlargement of the prostate. The main symptom was nocturnal frequency and he was warned by the surgeon that this particular symptom might not be improved by the operation. This has been the case. Are there any drugs which could help?

An appropriate successful elective transurethral prostatectomy for benign prostatic hypertrophy will predictably relieve the patient's symptoms of bladder outflow obstruction-that is, hesitancy, poor flow, and terminal dribbling. The associated urinary frequency, however, due to the secondary effects of outlet obstruction on the bladder may not always resolve, although given time this usually improves. In the presence of outflow obstruction the detrusor muscle becomes hypertrophied, is of ten urodynamically unstable, N and this persists after surgical relief of the bladder outflow obstruction in approximately $20 \%$ of patients. It is important for the patient to complete a frequency/volume chart over a trial period of a week to record the time at which voiding occurs and the volume passed on each occasion, together with $N$ an estimate of the daily intake of fluid, which may most simply be $N$ documented as the number of cups of fluid imbibed. For this particular patient it is particularly relevant to determine the total volume of urine passed at night, as occasionally this may be greater than the daytime volume. If he tends to acquire any ankle oedema during the day, due most commonly to some congestive cardiac failure, this will be reabsorbed when he is recumbent and result in nocturnal frequency. A morning diuretic may help control this problem together with restricting his fluid intake, particularly in the evening. Treatment with intranasal DDAVP snuff before retiring will reduce the volume of urine produced at night, again with advice to restrict the intake of fluid in the late evening. Often the nocturnal frequency in the case in question is due to the duration of this symptom before operation and has become something of a routine or habit and it is well worth trying the effects of night sedation with the addition of $200 \mathrm{mg}$ of cetiprin before retiring. 